\title{
Salen-type additives as corrosion mitigator for Ni-W alloys: Detailed electronic/ atomic-scale computational illustration
}

\author{
Pramod Kumar Uppalapati ${ }^{1}$, Avni Berisha ${ }^{2}$, Krishnasamy Velmurugan ${ }^{3}$, Ajit Khosla ${ }^{4}$, and \\ Tongxiang Liang ${ }^{1}$ \\ ${ }^{1}$ Jiangxi University of Science and Technology School of Materials and Chemical \\ Engineering \\ ${ }^{2}$ Chemistry Department of Natural Sciences Faculty, University of Prishtina \\ ${ }^{3}$ Nanjing University of Aeronautics and Astronautics College of Material Science \& \\ Technology \\ ${ }^{4}$ Yamagata University Faculty of Engineering Graduate School of Science and Engineering
}

October 23, 2020

\begin{abstract}
It is imperative to study the long term corrosion problems of nickel alloys in acidic medium due to breakdown of their passitive oxide. Focus of this work is to enhance the knowledge of adsorption of organic additives (OPD \& PPD) onto the Ni-W alloy surface. Deducing the scenario of competitive adsorption of salen-type symmetrical Schiff bases (OPD, and PPD) as additive molecules on Ni-W alloy surface at molecular level was studied by Density Functional Theory (DFT), Monte Carlo simulation (MC), Molecular Dynamics simulation (MD) and Radial Distribution Function (RDF) analysis. Obtained intrinsic molecular parmaters from DFT shows a strong conformity to the corrosion effeciencies of experimental results. Higher polarization value of 650.707 a.u (PPD) explicates its electron donating ability onto the alloy surface. Higher binding energy (Ebinding=1132.241 $\mathrm{kJ} / \mathrm{mol}$ ) and spatial orientation of PPD molecule portrays the closest contacts between active atoms and alloy surface. Significant findings from DFT global descriptors, MC, MD and RDF analysis ratifies the corrosion effeciencies (PPD > OPD) of experimental outcomes, which correlates positively with the larger isomeric spacer. Overall, the present study, reports offers the corrosion inhibition resistance impact of OPD \& PPD additives, revealing the fact of PPD as effective one and OPD as moderate ones for Ni-W alloys.
\end{abstract}

\section{Introduction}

Interaction of metallic alloy with aggressive ions $\left(\mathrm{Cl}^{-}, \mathrm{SO}_{4}{ }^{2-}, \mathrm{NO}_{3}{ }^{-}\right)$and $\mathrm{O}_{2}$ through the coating defects; establishes the corrosion products, diminishing the lifetime of steel or copper components and durability of assets. This corrosion is of inevitable in definite to the aerospace, automotive, structural engineering, oil and gas (energy) industries. ${ }^{1-3}$ In order to avert the financial drainage and to combat the coating deterioration, the application of protective coatings is one of the proficient methods. Most extant literature reported that Ni-W coatings were considered as ennobling alternate to chromium based (hexavalent) coatings. The governing factors those demerits the hard chrome is: low propulsion power of chromium (hexavalent) ions and its toxicity in the electrolyte bath, high consumption of electricity, low cathodic current density, and crucially a high chance of failure and in execution due to its residual tensile stress and cracks. ${ }^{4,5}$ Its superlative properties made it to applicable in many technological applications like faucets, springs, magnetic heads and relays ${ }^{6}$ and in particular as an electrode for $\mathrm{H}_{2}$ electrocatalysis. ${ }^{7}$ The traditional macroscopic scale experimental evaluations (Tafel slope, A.C. Electrochemical impedance spectroscopy, Weight loss measurements. etc) have paved a way in revealing the electrochemical behavior and kinetics of corrosion process occurring at the 
juncture of metal or alloy/corrosive solution. Nevertheless, the above mentioned techniques have left some caveats, which are to be dealt with. Researchers of corrosion science crave for in knowing the (i) potential correlation between the intrinsic electronic properties and inhibition mechanism, (ii) nature of reactive groups that aids in the organic adsorptions onto the surface of metals/alloys, and (iii) orientation of additive molecule over the alloy surface, which dictates the surface binding propensity. ${ }^{8}$ To an answer of above all, sophisticated and efficient computational simulations (DFT, MC, MD,RDF, Fukui indices etc) came into light to be dealt with the structure-reactivity relationship of additive/inhibitor ${ }^{9,10}$ in revealing the mechanism and the key role of each atoms or functional groups of the additive for electrodeposition ${ }^{11,12}$ and predominantly to corroborate single point corrosion experimental data. ${ }^{13,14}$ The accurate and precise information (molecular properties) like polarizability, excitation energies, electron donating ability, etc throws up a light in encoding the design of typical additive ${ }^{15,16}$ and intervene in exact synthesis strategy of additive molecule, cutting down the time and cost associated with exhaustive experimentations. ${ }^{17}$ Furthermore, greenness and novelty of the said computational techniques aids in avoiding the consumption or release of reductant malicious substances into the ecosystem, contrasting empirical pathways. ${ }^{18}$

On the continuation of our previous work, ${ }^{19}$ herein we have theoretically investigated the corrosion behaviors of salen-type ligand (OPD and PPD) which comprising of ortho- and para-phenylenediamine tethered hydroxy naphthalene, respectively on $\mathrm{Ni}-\mathrm{W}$ alloys in $\mathrm{H}_{2} \mathrm{SO}_{4}$ medium. The unique features of these OPD and PPD containing ample electron-rich aromatic centers (13 $\pi$-electrons) along with two nitrogen and oxygen atoms and their delocalization could improve the metal-inhibitor interactions via coordination bonding. In addition, by introducing isomeric spacers on salen-type ligands that prominently affects the numerous factors, such as electron-donating ability, nature of bonding, hardness/softness, rate of adsorption, molecular orientations, the distance between two layers (Ni-W and ligand), etc., and thus undeniably challenging to determine those issues from experimentally. Keep in mind, we have systematically examined the aforementioned issues with the aid of DFT, MC, MD, and RDF and thus compared with experimental results.

\subsection{Theoretical calculations}

\subsection{DFT analysis}

DFT analysis were performed through the $\mathrm{Dmol}^{3}$ program from Biovia. m-GGA approximation employing the M11-L functional ${ }^{20}$ and the numerical plus polarization basis set $(\mathrm{DNP})^{21}$ were utilized for geometry optimizations. Sulphuric acid as a solvent in the DFT calculations is incorporated through the Conductor-like Screening Model (COSMO). ${ }^{22}$

\section{2 $M C$ and $M D$ simulation}

In these simulation, the Ni-W surface with $\mathrm{OPD}$ and PPD interactions, respectively were performed in the simulated corrosion environment by using the 6 atom-thick layer unit cell of Ni-W (110) surface (under periodic boundary condition) formed through the use of Virtual Crystal Approximation (VCA). The size of the slab model employed in the calculations was: $22.427 \AA$ x $22.427 \AA$ x $8.265 \AA$ with and contained an addition of a $25 \AA$ vacuum layer at $\mathrm{C}$ axis that embedded $380 \mathrm{H}_{2} \mathrm{O}$ molecules/1 OPD/PPD molecule $/ 20$ $\mathrm{H}_{3} \mathrm{O}^{+}+10 \mathrm{SO}_{4}{ }^{2-}$ ions.

MD was attained via NVT canonical ensemble at $25^{\circ} \mathrm{C}$, with a simulation time of $0.5 \mathrm{~ns}\left(1 \mathrm{fs}\right.$ time step). ${ }^{23-25}$ The $\mathrm{T}$ control maintained by the Berendsen thermostat. The very often employed COMPASSII forcefield was employed for MC and MD calculations. ${ }^{23-28}$ The RDF studies is performed on the total timescale of the MD trajectory. ${ }^{25,28}$

\subsection{Results and Discussion}

\subsection{Electronic-scale results}

The optimized structures, highest occupied molecular orbital (HOMO), lowest unoccupied molecular orbital (LUMO) and molecular electrostatic potential (MEP) surfaces of the adopted molecules are shown inFigure 1. It reveals that electron densities of the OPD and PPD in HOMO are distributed along the entire rings 
of the additives and it is most dense on the part of the ring that contains nitrogen $(\mathrm{N})$ and oxygen $(\mathrm{O})$ atoms. These structural units of the additives have the greater ability to distribute their electron density with the surface of Ni-W alloy. This sharing of electrons has a consequence of formation of an organic film that prevents the corrosion of the surface by acting as a barrier. ${ }^{25,29}$ Electron densities of both additives in LUMO are occupied on the spacer phenylene ring nearby the $\mathrm{N}$ and $\mathrm{O}$ atoms; implying that this is the region where the electron acceptation from the electron rich surface takes place. The HOMO and LUMO electron density distributions of both additives played an equal significance in the surface adsorption of additive onto the surface of Ni-W alloy via electro-donation/acceptation pathways.

In general, the higher value of $\mathrm{E}_{\mathrm{HOMO}}$ of the inhibitor have greater tendency to share their electrons. Herein, PPD would reflect an somewhat enhanced adsorption on the surface of $\mathrm{Ni}-\mathrm{W}$ alloy via non-bonding electrons located on $\mathrm{N}$ and $\mathrm{O}$ atoms to the vacant d-orbitals of $\mathrm{Ni}$ and $\mathrm{W}$ surface atoms. ${ }^{29,30}$ With respect to the energy gap $(\Delta \mathrm{E})$, it is one of the crucial indices, which signifies the intensity of chemical reactivity towards corrosion inhibition. Furthermore, this parameter reveals the donating ability, chemical stability, softness and polarizibility of additive/inhibitor. ${ }^{17,31,32}$ From Table.1, it is reflective that separation energy (or) energy gap of PPD molecule (-2.202) is lower in comparative with that of OPD molecule (-2.586). This outcome implies that a lesser amount of energy is needed for a PPD molecule inorder to remove an outer orbital electrons, ${ }^{33}$ which ennobles its inhibition capacity.

The various parameters with their respective values gained from DFT analysis are shown in Table $1 .{ }^{23,25,28}$ The adsorptions of OPD \& PPD onto the alloy surface are further backed from their relatively soft electron affinities/high ionization potentials, which-providing an identical proficiency to swap electrons to the Ni-W alloy surfaces (Table 1). ${ }^{23,28}$

Furthermore, inhibitory effectiveness of an organic molecule is well related with its global softness $(\sigma)$ and hardness $(\eta)$. The chemical descriptor global hardness, which is an inverse of global softness, describes the level of molecular resistance to the charge transfer and electron cloud polarization and its reactivity in combat of acidic corrosion of metals. ${ }^{34-36}$ The sizable values of high chemical softness (0.736) and low global hardness (1.360) obtained for PPD molecule, emphasis its burly reactivity towards corrosion inhibition and lower resistance towards charge transfer and electron cloud polarization. Conversely, OPD molecule resulted in high hardness (1.369) and a very low softness (0.730) values with that of PPD molecule. Maximum hardness of OPD molecule, flaunt its larger kinetic stability ${ }^{31}$ and higher resistance to charge transfer, thereby illustrating its reluctance to react. ${ }^{18}$ Moreover, a sizable and low values of the chemical softness (0.736) and hardness (1.360) are suggests a a strong adsorptive tendency of PPD molecules on the Ni-W surface.

Global electrophilicity index $(\omega)$ is one of the prime quantum chemical descriptor, which deduces the information on the stabilization of molecular system through electron donation or acceptance. ${ }^{37}$ Greater value of $(\omega)$ has higher electron donating ability of organic moiety to the empty metal d-orbitals. ${ }^{38}$ The obtained $(\omega)$ values (Table 1 ) validate that PPD additive with higher $\omega=4.316$, had the most reactivity to attach onto the alloy surface, providing greater corrosion inhibition. It is worth noting that the greater electron donating ability affidavits the stronger adsorption mechanism of PPD molecule onto the alloy surface. ${ }^{39}$

Polarization is one of the polarity related quantum descriptor, which describes the distribution and distortion of electron density. ${ }^{40}$ Moreover, it clearly facilitates the extent of polarization, which determines the degree of experimental corrosion efficiency ${ }^{41}$ Here in the present study the following results were reported with respect to the polarizability; $\alpha=572.971$ a.u (OPD) and $\alpha=650.707$ a.u respectively. Interesting assets can be inferred from the computed results. Higher value of polarizability obtained for in the case of PPD additive, stresses the easy electron density distribution from the molecule onto the metal surface, which means that the strong electron affinities with alloy surfaces. Further, the higher polarizability value $(\alpha=650.707$ a.u) in comparative with that of OPD ( $\alpha=572.971 \mathrm{a} . \mathrm{u})$ explicate the higher surface coverage and sturdy adsorption for $\mathrm{Ni}-\mathrm{W}$ alloy protection ${ }^{40,42}$ representing a more effective interaction as the isomeric spacer differ in its position. ${ }^{19}$ The trend in the enhancement of polarizabilities for compounds (PPD $>$ OPD) is consistent with the order of experimental corrosion efficiency results. ${ }^{19}$ 
Mulliken atomic charges (MAC) and Fukui function have been employed as vital tools for evaluating the accountable atomic sites in adsorbed materials. ${ }^{27,28}$ Based on this approach, OPD and PPD additives showed the highest negative values of MAC procured on N and O atoms. Similarly, the Fukui indices provide the valuable information about reactive sites, nucleophilic and electrophilic properties of the inhibitor molecules. The Fukui values on these atoms as revealed by MAC, atoms imply that they provide the electron density for the Ni-W surface coordination and back-donation (showing their dual character in this process). These parts of molecules with a prevalence of the electron densities are noticeable (in red) in Figure 1, and with respect to MAC (presented jointly with the Fukui indices values in the Figure 2). The full computed condensed Fukui functions and the results of the local reactivity indices of OPD and PPD additive molecules are tabulated in Table $2 \& 3$.

\subsection{Classical atomic-scale simulations}

Computational investigations (MC\&MD) based on classical physics have been preferred to get further perception about the nature of adsorption of additive molecules on the alloy substrate at atomic level. ${ }^{43,44,17}$

\subsubsection{Monte Carlo simulations}

It is of imperative in quantifying the various energetic outputs, to know the preferential adsorption and orientation of the adopted additives on the alloy surface. ${ }^{45}$ The energy values (in term of different contributions) during the random MC configuration search are shown in Figure 3. From this figure 3, the total average energy reached the equilibrium at after $3000000 \mathrm{MC}$ suggesting that additives reached the low energy stable arrangement. The interaction of the OPD \& PPD onto the Ni-W surface gives a mean to evaluate the required energies for this adsorption. The quantitative adsorption energy (Eads) is calculated by using equation $2: 25,27,46,47$

$$
E_{\text {adsorption }}=E_{\mathrm{Ni}-W(110) \mathrm{CPQ} \text { orMPQ }}-\left(\mathrm{Ni}-W_{(110)}+E_{\mathrm{OPD} \text { or PPD }}\right) \quad . \quad \text { Equation } 2
$$

whereNi-W (110) OPD or PPDis the total energy of the simulated corrosion system, $\mathrm{E}_{\mathrm{Ni}-\mathrm{W}}$, and $\mathrm{E}_{\mathrm{OPD}}$ or PPD is the total energy of the Ni-W(110) surface and free inhibitor.

The most stable or the low energy adsorption sites of organic additives (OPD \& PPD) in the vicinity of $\mathrm{Ni}-\mathrm{W}$ alloy surface and corresponding adsorption energetic outputs (Eads) obtained via a huge number of randomly configurations from Monte Carlo calculations were figured out in Figure 4. It is of significant in knowing the adsorption energy $\left(\mathrm{E}_{\text {ads }}\right)$ which denotes to the sum of deformation energy and rigid adsorption energy of additive components. ${ }^{48}$ Additionally, $\mathrm{E}_{\text {ads }}$ corresponds to the release of energy, while the organic additives (OPD\&PPD) relaxed on the surface of alloy. The Max.adsorption energy distribution was found to be $-121.25 \mathrm{kcal} / \mathrm{mol}$ and $-195.55 \mathrm{kcal} / \mathrm{mol}$ for OPD \& PPD additive molecules respectively. A noticeable larger negative value of $\mathrm{E}_{\text {ads }}=-195.55 \mathrm{kcal} / \mathrm{mol}(\mathrm{PPD})$ infers that the adsorbed organic layer on the alloy surface is spontaneous and more stable, ${ }^{49}$ then the earlier molecular layer (OPD). Moreover, this higher negative value $\left(\mathrm{E}_{\mathrm{ads}}=-195.55 \mathrm{kcal} / \mathrm{mol}\right)$ evidence the fact that mere amount of energy is required for the PPD molecule for adsorption onto the Ni-W alloy surface ${ }^{45}$ intensifying the surface coverage area, thus providing a durable shield against corrosive suppressing agents. ${ }^{50}$

\subsubsection{Molecular dynamics simulations}

Further, the closer inspection of interfacial adsorption, strength of interaction ${ }^{51}$ and the relevancy between chemical species (OPD \& PPD) and Ni-W alloy surface in the simulated solvent $\left(\mathrm{H}_{2} \mathrm{So}_{4}\right)$ is discerned through MD simulations. ${ }^{52}$ Figure $\mathbf{5}$ displayed a flat-lying geometry with lowest energy configurations of OPD and PPD, respectively adsorbed on the Ni-W (110) surface in the simulated corrosion envirionment.. These results suggested that heteroatoms and spacer are responsible for the flat-lying geometry and denser adsorption (as supported by MAC and Fukui function). On closer inspection of the obtained snapshots (Figure 5) the flat-lying orientation of PPD molecules was greater with that of OPD molecules with distinctive slit. This variance in the orientation, ensures greater dispensation of electron density over the alloy surface, resulting 
in maximal blocking area with sturdy interactive forces. ${ }^{53,54}$ Further, an insight of faster movement of PPD additive molecules is seen towards the alloy surface through corrosive solution, comparative of OPD additive molecules. This faster motion, leads to greater relinquish of corrosive species ${ }^{55}$ evidencing the propensity of PPD molecules, in the robust barrier thin film formation on the alloy surface.

A notable two energetic outputs (Ebinding, Einteraction) were derived from MD simulations, which dictate the competitive adsorption potentiality of adopted additives onto the alloy surface. ${ }^{56}$ From Table 4 , a larger negative value $(-1132.24 \mathrm{kcal} / \mathrm{mol})$ of interaction energy is an evident of higher interactivity between PPD molecules and alloy surface. It also signifies of its higher stability and spontaneity of the thin film formation over the alloy surface. In addition, the higher negative interaction energy obtained for PPD molecule marks the expel of sulphuric acid molecules and stronger adsorption capability over the alloy surface. ${ }^{57}$ Another noted energetic descriptor is binding energy (Ebinding) proposing the extent of adsorption of organic molecules onto the alloy surface (Ni-W). Higher binding energy obtained for PPD molecule $(1132.241 \mathrm{~kJ} / \mathrm{mol})$ displays its higher binding affinity ${ }^{55}$ towards alloy surface than OPD molecule $(1074.38 \mathrm{~kJ} / \mathrm{mol})$. Further, higher Ebinding $(1132.241 \mathrm{~kJ} / \mathrm{mol})$ portrays its potential electro-donating ability of PPD additive by reason of larger isomeric spacer ${ }^{19}$ which mitigate the corrosion process. These energetic outputs ensure the ability of PPD additive molecules in greater aggregation, forming a dense molecular layer, ${ }^{58}$ limiting the access of corrosive species onto the surface of Ni-W alloy.

\subsubsection{Radial Distribution Function (RDF)}

$\mathrm{RDF}$ has proved as an important approach for the assessment of the adsorption process type present during the inhibitor adsorption: either a physical or chemisorption. In advancement to the MD simulations, RDF is employed to measure the bond lengths between the heteroatoms and the alloy surface, which dictates the interaction modes (chemisorptions/physisorption). ${ }^{59}$ Further, this analysis reveals the degree of resistance/ rigidity of the adsorbed organics on the alloy surface. ${ }^{60}$ Emergence of the peak in the RDF graph offers a simple distinction of the involved process. The appearance of the peak from the distance 1 to $3.5 \AA$ is an indication of a chemisorption process, whereas in the case of physisorption RDF peaks are expected at longer distances $(>3.5 \AA)$. InFigure 6 , RDF values imparts the nature of intermolecular interactions (stronger/weaker) that occurred between alloy surface and the interacting atoms (nitrogen and oxygen atoms). Impressive findings are perceived in the presence of PPD molecule where the bond lengths of N-NiW \& O-Ni-W shown less than $3.0 \AA$, from the surface plane of the material illustrating the chemisorption process; i.e, stronger interactive forces which aids in effective bounding of PPD molecule onto the alloy surface ${ }^{61}$ However, the bond length of N-Ni-W \& O-Ni-W for OPD molecule, recorded closer to $3.5 \AA$, pointing out the physisorption; i.e, weaker interactive forces exhibiting a tenuous affinity towards the alloy surface. Overall, the outcomes of RDF results, speculate that PPD molecule exert the action of corrosion inhibition through chemisorption, predominantly by the electrovalent bonds ${ }^{55}$ inferring the higher tendency of PPD adsorption onto the alloy surface, thus safeguarding the Ni-W alloy against degradation. The schematic representation of adsorption of additives onto the alloy surface was figured out in Figure 7.

\section{Conclusion}

The present study was carried out using multipple theoretical approaches (DFT, MC, MD, RDF). which allows a relatively good reproduction of experimental corrosion results (EIS,Tafel). Similar order of protection efficiencies (PPD $>$ OPD) obtained experimentally was complemented with the parameters of DFT global descriptors, MC, MD and RDF analysis. Computed global descriptors like higher chemical softness (0.736), polarizability (650.707 a.u) and small energy gap (-2.202) obtained for PPD molecule; emphasize its corrosion suppressing characteristics. Fukui indices and Mulliken atomic charges depicted the adsorption centers of the PPD and OPD additives. Higher binding energy (Ebinding $=1132.241 \mathrm{~kJ} / \mathrm{mol}$ ) and larger negative interaction energy (Einteraction $=-1132.241 \mathrm{kcal} / \mathrm{mol}$ ) and greater flat-lying adsorption orientation of PPD molecule affirms the reduction in diffusion of corrosive species. Stronger interactive forces i.e chemisorption between Ni-W alloy and additive molecules was revealed through RDF analysis. Larger negative value of adsorption energy (Eadsorption= $-195.55 \mathrm{kcal} / \mathrm{mol}$ ) from monte carlos, authenticates its spontaneity, stability and higher surface coverage area; fabricating an packed additive film. Finally, a fruitful insight, 
providing a pellucid picture of interfacial interactions occurring between Ni-W alloy and additive molecules (OPD \& PPD) was deduced in correlation with the previously reported experimental results.

\section{Acknowledgments}

The present work is financially supported by the National Natural science Foundation of China (grant no. 51871114) and the authors thank Jiangxi University of Science and Technology for providing necessary facilities. Avni Berisha gratefully acknowledges the support from the Ministry of Education, Science and Technology of Kosovo (Nr.2-5069) for providing the computing resources.

\section{References}

1. A. Gibb, A. Vorobjovs, Z. Jagoda, J. Winiarski and A. Stankiewicz, Trans. IMF , 98,15 (2020).

2. M. Finsgar and J. Jackson, Corros. Sci. , 86 , 17 (2014).

3. B. D. B. Tiu and R. C. Advincula, React. Funct. Polym. ,95, 25 (2015).

4. M. H. Allahyarzadeh, M. Aliofkhazraei, A. R. Rezvanian, V. Torabinejad and A. R. Sabour Rouhaghdam, Surf. Coat. Technol. ,307, 978 (2016).

5. N. P. Wasekar, S. M. Latha, M. Ramakrishna, D. S. Rao and G. Sundararajan, Mater. Design, 112 , 140 (2016).

6. N. Eliaz and E. Gileadi, eds. C. G. Vayenas, R. E. White, and M. E. Gamboa-Aldeco, p. 191, Springer (2008).

7. M. P. Quiroga Arganaraz, S. B. Ribotta, M. E. Folquer, G. Benitez, A. Rubert, L. M. Gassa, M. E. Vela and R. C. Salvarezza, J. Solid State Electrochem. , 17, 307 (2013).

8. C. Verma, H. Lgaz, D. K. Verma, E. E. Ebenso, I. Bahadur and M. A. Quraishi, J. Mol. Liq. , 260 , 99 (2018).

9. H. Shokry, J. Mol. Struct. , 1060 , 80 (2014).

10. H. Mi, G. Xiao and X. Chen, Comput. Theor. Chem. ,1072, 7 (2015).

11. C. Wang, J. Zhang, P. Yang and M. An, Electrochim. Acta ,92, 356 (2013).

12. Z. Feng, L. Ren, J. Zhang, P. Yang and M. An, J. Electrochem. Soc. , 163, D544 (2016).

13. I. B. Obot, E. E. Ebenso and M. M. Kabanda, J. Environ. Chem. Eng. , 1 , 431 (2013).

14. D. A. Winkler, M. Breedon, A. E. Hughes, F. R. Burden, A. S. Barnard and T. G. Harvey, Green Chem., 16, 3349 (2014).

15. M. A. Bedair, J. Mol. Liq. , 219, 128 (2016).

16. H. Lgaz, R. Salghi, K. Subrahmanya Bhat, A. Chaouiki, Shubhalaxmi and S. Jodeh, J. Mol. Liq. , 244, 154 (2017).

17. S. Kr. Saha, A. Hens, N. C. Murmu and P. Banerjee, J. Mol. Liq. , 215 , 486 (2016).

18. A. H. Tantawy, K. A. Soliman and H. M. A. El-Lateef, J. Clean. Prod. , 250 , 119510 (2020).

19. U. Pramod Kumar, T. Liang, C. Joseph Kennady, R. Nandhakumar and J. Prabhu, ACS Omega , 5 , $3376(2020)$.

20. R. Peverati and D. G. Truhlar, Phys. Chem. Chem. Phys. ,14, 11363 (2012).

21. Y. Inada and H. Orita, J. Comput. Chem. , 29 , 225 (2008).

22. A. Klamt, Wiley Interdiscip. Rev. Comput. Mol. Sci. ,8 , e1338 (2018).

23. R. Hsissou, S. Abbout, R. Seghiri, M. Rehioui, A. Berisha, H. Erramli, M. Assouag and A. Elharfi, J. Mater. Res. Technol. , 9, 2691 (2020).

24. O. Dagdag, A. Berisha, Z. Safi, O. Hamed, S. Jodeh, C. Verma, E. E. Ebenso and A. E. Harfie, J. Appl. Polym. Sci. , 13748402 (2020).

25. O. Dagdag, R. Hsissou, A. El Harfi, A. Berisha, Z. Safi, C. Verma, E. E. Ebenso, M. E. Touhami, and M. E. Gouria, Surf. Interfaces ,18, 100454 (2020).

26. H. Sun, Z. Jin, C. Yang, R. L. C. Akkermans, S. H. Robertson, N. A. Spenley, S. Miller and S. M. Todd, J. Mol. Model. , 22, 1 (2016).

27. S. Abbout, M. Zouarhi, D. Chebabe, M. Damej, A. Berisha and N. Hajjaji, Heliyon, 6 , e03574 (2020). 
28. O. Dagdag, A. Berisha, Z. Safi, S. Dagdag, M. Berrani, S. Jodeh, C. Verma, E. E. Ebenso, N. Wazzan and A. E. Harfi, J. Appl. Polym. Sci., (2020). Doi:10.1002/app.49003.

29. V. V. Mehmeti and A. R. Berisha, Front. Chem. , 5, 61 (2017).

30. A. S. Fouda and A. S. Ellithy, Corros. Sci. , 51,868 (2009).

31. N. Abad, H. Lgaz, Z. Atioglu, M. Akkurt, J. T. Mague, I. H. Ali, I.-M. Chung, R. Salghi, E. M. Essassi and Y. Ramli, J. Mol. Struct. ,1221, 128727 (2020).

32. K. O. Sulaiman, A. T. Onawole, O. Faye and D. T. Shuaib, J. Mol. Liq. , 279 , 342 (2019).

33. H. M. A. El-Lateef, V. M. Abbasov, L. I. Aliyeva, E. E. Qasimov and I. T. Ismayilov, Mater. Chem. Phys. , 142, 502 (2013).

34. W. Kohn and L. J. Sham, Phys. Rev. , 140 , A1133 (1965).

35. C. M. Fernandes, V. G. S. S. Pina, L. X. Alvarez, A. C. F. de Albuquerque, F. M. dos Santos Junior, A. M. Barrios, J. A. C. Velasco and E. A. Ponzio, Colloids Surf. A , 599 , 124857 (2020).

36. W. Yang and R. G. Parr, Proc. Natl. Acad. Sci. U. S. A. ,82, 6723 (1985).

37. R. G. Parr, L. V. Szentpaly and S. Liu, J. Am. Chem. Soc. ,121, 1922 (1999).

38. N. Palaniappan, I. Cole, F. Caballero-Briones, S. Manickam, K. R. Justin Thomas and D. Santos, RSC Adv. , 10,5399 (2020).

39. N. Palaniappan, I. S. Cole, K. Damodaran, A. Kuznetsov, K. R. Justin Thomas and K. Balasubramanian, $R S C A d v$. 10,12151 (2020).

40. C. T. Ser, P. Zuvela and M. W. Wong, Appl. Surf. Sci. ,512, 145612 (2020).

41. J. M. Mir, R. C. Maurya and P. K. Vishwakarma, J. Modern Sci. ,3 , 212 (2017).

42. E. E. Ebenso, K. F. Khaled, S. K. Shukla, A. K. Singh, N. O. Eddy, M. Saracoglu, L. C. Murulana, F. Kandemirli, T. Arslan and I. B. Obot,Int. J. Electrochem. Sci. , 7 , 5643 (2012).

43. A. Dehghani, G. Bahlakeh, B. Ramezanzadeh and M. Ramezanzadeh, J. Mol. Liq. , 279 , 603 (2019).

44. W. Zhang, Y. Liu, Y. Zhang, L.-J. Wang, Y.-C. Wu and H.-J. Li,New J. Chem., 44, 6464 (2020).

45. H. Bourzi, R. Oukhrib, B. E. Ibrahimi, H. A. Oualid, Y. Abdellaoui, B. Balkard, M. Hilali and S. E. Issami, Surf. Sci. , 702,121692 (2020).

46. L. Guo, S. T. Zhang, W. P. Li, G. Hu and X. Li, Mater. Corros. ,65 , 935 (2014).

47. R. Hsissou, B. Benzidia, M. Rehioui, M. Berradi, A. Berisha, M. Assouag, N. Hajjaji and A. Elharfi, Polym. Bull. , 77, 3577 (2020).

48. K. F. Khaled and A. El-Maghraby, Arabian J. Chem. , 7, 319 (2014).

49. M. Rbaa, A. S. Abousalem, M. E. Touhami, I. Warad, F. Bentiss, B. Lakhrissi and A. Zarrouk, J. Mol. Liq ., 290,111243 (2019).

50. F. Poshtiban, G. Bahlakeh and B. Ramezanzadeh, Appl. Surf. Sci. , 495, 143582 (2019).

51. M. El Faydy, H. About, F. Benhiba, B. Lakhrissi, A. Guenbour, F. Bentiss, I. Warad, E. E. Ebenso and A. Zarrouk, Surf. Interfaces , 20, 100575 (2020).

52. X. Zhang, W. Li, G. Yu, X. Zuo, W. Luo, J. Zhang, B. Tan, A. Fu and S. Zhang, J. Mol. Liq ., 318 , $114080(2020)$.

53. M. A. Bedair, S. A. Soliman, M. F. Bakr, E. S. Gad, H. Lgaz, I.-M. Chung, M. Salama and F. Z. Alqahtany, J. Mol. Liq. ,317, 114015 (2020).

54. L. N. Emembolu, O. D. Onukwuli, C. J. Umembamalu and C. O. Aniagor, J. Bio- and Tribo-Corrosion , 6,128 (2020).

55. H. Lgaz, R. Salghi, S. Masroor, S.-H. Kim, C. Kwon, S. Y. Kim, Y.-J. Yang and I.-M. Chung, J. Mol. Liq. , 308 , 112998 (2020).

56. M. Murmu, S. Kr. Saha, N. C. Murmu and P. Banerjee, Corros. Sci. , 146 , 134 (2019).

57. J. Saranya, F. Benhibad, N. Anusuya, R. Subbiah, A. Zarrouk and S. Chitra, Colloids Surf. A, 603 , $125231(2020)$.

58. D. Wang, Y. Li, B. Chen and L. Zhang, Chem. Eng. J. ,402, 126219 (2020).

59. A. Chaouiki, H. Lgaz, R. Salghi, M. Chafiq, H. Oudda, Shubhalaxmi, K.S. Bhat, I. Cretescu, I. H. Ali, R. Marzouki and I-M. Chung, Colloids Surf. A , 588, 124366 (2020).

60. M. E. Belghiti, S. Bouazama, S. Echihi, A. Mahsoune, A. Elmelouky, A. Dafali, K. M. Emran, B. Hammouti and M. Tabyaoui, Arab. J. Chem. , 13, 1499 (2020). 
61. W. Luo, W. Li, J. Tan, J. Liu, B. Tan, X. Zuo, Z. Wang and X. Zhang,J. Mol. Liq. , 314, 113630 (2020).

\section{Hosted file}

new figures.pdf available at https://authorea.com/users/369584/articles/488403-salen-typeadditives-as-corrosion-mitigator-for-ni-w-alloys-detailed-electronic-atomic-scalecomputational-illustration

\section{Hosted file}

new tables.pdf available at https://authorea.com/users/369584/articles/488403-salen-typeadditives-as-corrosion-mitigator-for-ni-w-alloys-detailed-electronic-atomic-scalecomputational-illustration 